\title{
Adaptive Study Design Indicator
}

National Cancer Institute

\section{Source}

National Cancer Institute. Adaptive Study Design Indicator. NCI Thesaurus. Code

C146995.

A study design which includes a prospectively planned opportunity for modification of one or more specified aspects of the study design and/or hypotheses based on analysis of data, usually interim data. 